\title{
Mucosal adaptation to aspirin induced gastric damage in humans. Studies on blood flow, gastric mucosal growth, and neutrophil activation
}

\author{
J W Konturek, A Dembinski, R Stoll, W Domschke, S J Konturek
}

\begin{abstract}
The gastropathy associated with the ingestion of non-steroidal anti-inflammatory drugs (NSAIDs) such as aspirin is a common side effect of this class of drugs, but the precise mechanisms by which they cause mucosal damage have not been fully explained. During continued use of an injurious substance, such as aspirin, the extent of gastric mucosal damage decreases and this phenomenon is named gastric adaptation. To assess the extent of mucosal damage by aspirin and subsequent adaptation the effects of 14 days of continuous, oral administration of aspirin ( $2 \mathrm{~g}$ per day) to eight healthy male volunteers was studied. To estimate the rate of mucosal damage, gastroscopy was performed before (day 0 ) and at days 3, 7, 14 of aspirin treatment. Gastric microbleeding and gastric mucosal blood flow were measured using laser Doppler flowmeter and mucosal biopsy specimens were taken for the estimation of tissue DNA synthesis and RNA and DNA concentration. In addition, the activation of neutrophils in peripheral blood was assessed by measuring their ability to associate with platelets. Aspirin induced acute damage mainly in gastric corpus, reaching at day 3 about 3.5 on the endoscopic Lanza score but lessened to about 1.5 at day 14 pointing to the occurrence of gastric adaptation. Mucosal blood flow increased at day 3 by about $50 \%$ in the gastric corpus and by $88 \%$ in the antrum. The in vitro DNA synthesis and RNA concentration, an index of mucosal growth, were reduced at day 3 but then increased to reach about $150 \%$ of initial value at the end of aspirin treatment. The gastric microbleeding rate rose from about $0.38 \mathrm{ml} /$ day at day 0 to about $7.7 \mathrm{ml} /$ day at day 3 but then decreased significantly to virtually normal values at the end of the study. The neutrophil/platelet adherence showed significant increase during aspirin treatment. It is concluded that the treatment with aspirin in humans induces gastric adaptation to this agent, which entails the increase in mucosal blood flow, the rise in neutrophil activation, and the enhancement in mucosal growth.

(Gut 1994; 35: 1197-1204)
\end{abstract}

The association between gastroduodenal injury and the use of non-steroidal anti- inflammatory drugs (NSAIDs) such as aspirin has been shown in experimental animals ${ }^{1}$ and humans. ${ }^{2}$ How aspirin and other NSAIDs damage the gastroduodenal mucosa or delay its regeneration is not clearly understood. The deleterious effects of aspirin on gastroduodenal mucosa are generally attributed either to the direct damage of mucosal cells or to its ability to reduce the formation of prostaglandins. ${ }^{3}$ The inhibition of cyclo-oxygenase activity increases the susceptibility of gastric mucosa to injury while prostaglandins exhibit protective effects on the mucosa. ${ }^{4}$ Support for this mechanism is provided by the findings that NSAIDs affect various mucosal defence lines such as $\mathrm{HCO}_{3}{ }^{-}$secretion, mucus synthesis, and mucosal barrier. ${ }^{34}$ The effects of NSAIDs on mucosal blood flow, an important component of mucosal protection, remain controversial. In some studies mucosal blood flow was shown to be decreased by aspirin, ${ }^{5}$ whereas in others ${ }^{6}$ an increase in blood flow in the gastric mucosa was seen. On the other hand, aspirin and indomethacin have been shown to induce a microvascular damage ${ }^{7}$ and the extent of mucosal damage evoked by NSAIDs has not been closely correlated to the inhibition of mucosal cyclooxygenase activity.

Previous papers ${ }^{8-10}$ reported that the gastric mucosal injury in humans lessens or resolves despite the continued treatment with aspirin and other NSAIDs. This phenomenon of gastric mucosal adaptation associated with prolonged use of aspirin is well reported in animal studies ${ }^{11} 12$ but the mechanisms whereby the mucosa adapts to the damage remain uncertain.

Recently, it has been proposed that adherent leucocytes $^{13}$ play an important part in the pathogenesis of NSAID induced gastropathy. ${ }^{14}$ This was supported by studies of Wallace et $a l^{15}$ and Lee et al ${ }^{16}$ who saw that the administration of monoclonal antibody against the leucocyte adhesion glycoprotein or anti-neutrophil serum largely prevented the microvascular injury caused by NSAIDs including aspirin in rats. Neutrophils release various mediators, such as proteases, and free radicals ${ }^{17}$ and their activation is mediated by newly recognised selectin $P$ called platelet activation dependent granule external membrane protein (PADGEM). ${ }^{18}$ This selectin is responsible both for the platelet/neutrophil association and neutrophil/ endothelium adherence. As activation of neutrophils seemed to be important in the development of gastric erosions after administration of indomethacin in rats, ${ }^{15}$ it has 
become very interesting to assess the activity of neutrophils during the adaptation of the human stomach to aspirin.

NSAIDs increase the rate of proliferation in endoscopically normal gastric epithelium of patients with arthritis. ${ }^{19}$ This may also be one of the mechanisms underlying gastric adaptation to repeated NSAID treatment because a mucosal cell turnover is an important factor for gastric regeneration and mucosal integrity. 1920

The aim of this study was to evaluate the ability of human gastric mucosa to adapt to prolonged aspirin treatment and to find out if mucosal adaptive changes induced by aspirin are related to changes in mucosal blood flow, neutrophil activation, and mucosal growth.

\section{Methods}

\section{SUBJECTS}

Studies were carried out on eight healthy male volunteers between the ages 20 and 24 and weighing $67-80 \mathrm{~kg}$. The subjects were requested to refrain from taking alcohol and drugs for two weeks before and during the study. All of them were in good health without any previous or present gastrointestinal disease and with normal laboratory values for blood chemistry and haematology. The volunteers were not requested to follow any dietary restriction or to modify their lifestyle during the period of treatment. All subjects had an assessment before the study including gastroduodenoscopy and $\mathrm{C}^{13}$ urea breath test for Helicobacter pylori.

This study was approved by the appropriate institutional review committee, and all subjects gave informed consent.

\section{STUDY DESIGN}

After the pre-study assessment, each subject received aspirin treatment. Oral aspirin was taken three times daily; one tablet $500 \mathrm{mg}$ unbuffered aspirin (Bayer, Germany), was taken after breakfast at 0800 , one at 1600 , and two before bedtime as the daily total dose was 2 g. Similar treatment was continued for 14 consecutive days.

\section{ASSESSMENTS}

Subjects had an endoscopy and were studied for microbleeding, gastric mucosal blood flow, salicylate plasma concentration, and granulocyte/platelet interaction determined 24 hours before the start of aspirin treatment. The tests were then repeated at days 3,7 , and 14 of aspirin treatment, and additionally twice namely: two and four days after aspirin treatment had ended. Venous blood samples were withdrawn to measure plasma salicylate concentration as described before. ${ }^{21}$ Blood was taken for the measurement of platelet adherence to neutrophils. For this last purpose the 'rosette' formation test was used according to Jungi et al. ${ }^{22}$ Polymorphonuclear leucocytes $(\mathrm{PMN})$ were isolated with the Ficol paque technique according to Byoum. ${ }^{23}$ Attention was paid to minimise the contamination of platelets. Therefore blood was collected to sodium citrate $(3 \cdot 2 \%)$ and first centrifuged to obtain platelet rich plasma. Such platelet rich plasma was further used for isolation of platelets by gel filtration ${ }^{24}$ when the residual erythrocytes/PMN and monocyte fraction was mixed with $3 \%$ solution of dextran. After sedimentation the upper fraction contained PMN/monocyte cells and this fraction was used for the Ficol gradient isolation of PMN. The residual erythrocytes were removed with hypo-osmotical lysis. Both washed platelets and PMNs were coincubated in Tyrode solution for 20 minutes at $22^{\circ} \mathrm{C} .{ }^{22}$ The expression of PADGEM in platelets was induced by the addition of subthreshold proaggregatory concentration of thrombin (20-50 $\mathrm{mU})$. The PMN were examined in both stimulated and thrombin unstimulated platelets under water immersion by photomicroscope (Zeiss, Berlin, Germany).

The rate of gastric microbleeding was measured as follows: each volunteer swallowed a 16 French gauge orogastric tube. The stomach was rinsed of debris with $100 \mathrm{ml}$ of distilled water, then $100 \mathrm{ml}$ of test solution was instilled into the stomach for a 10 minute washing period. ${ }^{25}$ After five minutes of each period $2 \mathrm{ml}$ of phenol red as a marker in $10 \mathrm{ml}$ of water was introduced by the orogastric tube and dispersed in the stomach. After 10 minutes of each washing period the gastric content was siphoned out and collected. Three successive washouts were performed at 10 minute intervals. Test solution or phenol red was introduced into the stomach and the subjects performed a standard series of manoeuvres designed to ensure contact with the whole gastric mucosa and to permit the blood to accumulate in gastric washing. Blood rinsed from the stomach and accumulated in the gastric washing was quantified by the peroxidase activity of the haemoglobin. Gastric microbleeding during each 10 minute period was calculated after the correction for phenol red recovery. Mean gastric microbleeding for three 10 minute washing periods was calculated and expressed as bleeding rate in $\mathrm{ml} /$ day. Phenol red was measured spectrophotometrically at $\mathrm{pH} 10.5$ and a wave length of $560 \mathrm{~nm} .^{25}$ The $\mathrm{pH}$ of gastric washing was determined using glass electrode.

About 30 minutes after completion of gastric washing, the standard, unsedated, upper gastrointestinal endoscopy was performed by one investigator using an Olympus GIF $Q$ panendoscope to evaluate the mucosal damage using the Lanza score system. ${ }^{26}$ Grading score was from 0 - normal to 4 - large area of submucosal haemorrhage with active bleeding or widespread involvement in the stomach. During endoscopy, samples of gastric juice were obtained by aspiration through the suction channel of the gastroscope into a trap. Care was taken to ensure the channel was clear of any contaminating fluid. About $5 \mathrm{ml}$ aliquots of gastric juice were obtained from each subject, mixed with aprotinin (Trasylol, 


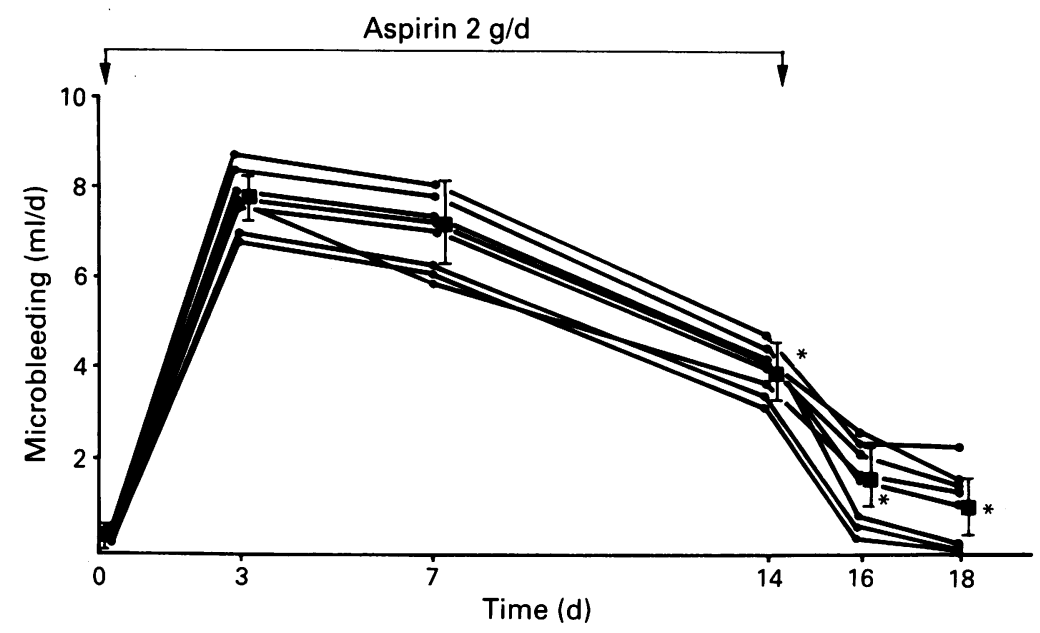

Figure 1: Gastric microbleeding in eight subjects treated with aspirin for 14 days and four days after aspirin treatment. Individual data and mean (SEM) are shown. ${ }^{\star}$ Shows significant $(p<0.001)$ changes compared with day 3 of treatment.

Bayer, Germany) to prevent epidermal growth factor degradation and frozen at $-70^{\circ} \mathrm{C}$ until radioimmunoassay using the technique described previously. ${ }^{27}$ Subjects were instructed not to swallow during and after gastric washings with all saliva being expectorated.

During endoscopy, the gastric blood flow was measured by the laser Doppler flowmetry technique using a novel generation of blood perfusion monitor (Laserflow, model BPM2, Vasamedics, St Paul, MN, USA). ${ }^{28}$ The flow probe (PR-436) was inserted down the biopsy channel of Olympus GIF $Q$ panendoscope and after five minutes of stabilisation the blood flow was measured under direct vision in the gastric fundus and antrum. The values of the flow $(\mathrm{ml} / \mathrm{min} / 100 \mathrm{~g})$ displayed on the digital panel meter were means of six measurements in the antrum and six in the corpus of the stomach, each measurement was made over a 10 second period required for the stabilisation of the recorded gastric blood flow. Two mucosal pinch biopsy specimens were taken from the gastric antrum and the corpus for the estimation of the DNA synthesis and RNA and DNA concentration in the gastric mucosa. The rates of DNA synthesis in

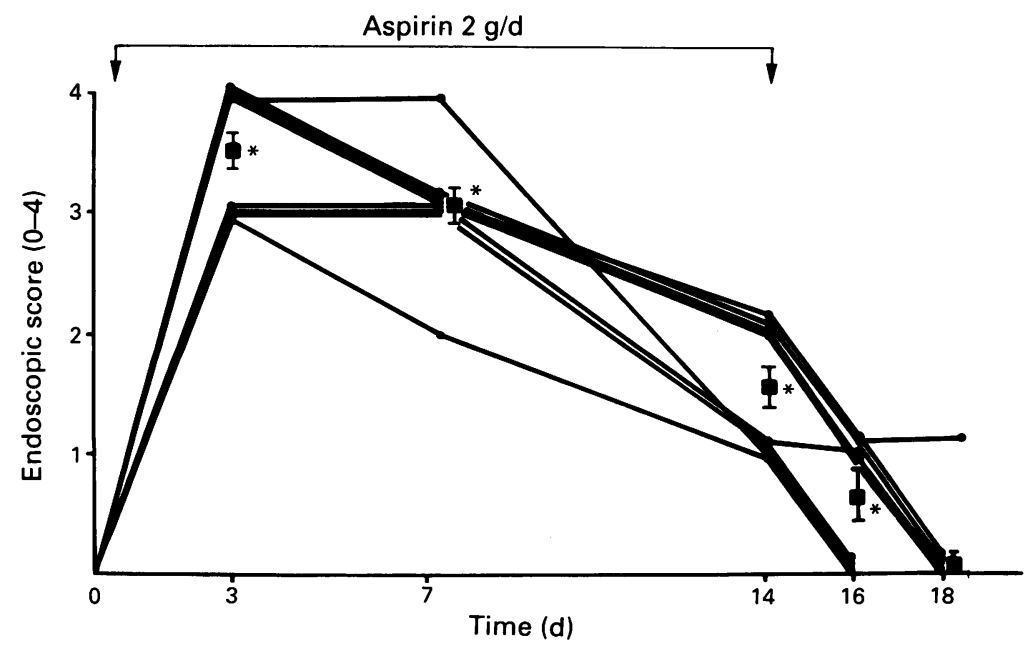

Figure 2: Endoscopic score of gastric mucosa in eight subjects treated with aspirin for 14 days and four days after aspirin treatment. Individual data and mean (SEM) are shown. $\star$ Shows significant changes $(p<0 \cdot 001)$ compared with control values. the mucosal biopsy specimens were measured by incubating the tissue at $37^{\circ} \mathrm{C}$ for 30 minutes in Eagle's minimal essential culture medium containing $2 \mu \mathrm{Ci} / \mathrm{ml} \quad\left[{ }^{3} \mathrm{H}\right]$ thymidine (5 $\mathrm{Ci} / \mathrm{mmol}$ Amersham, England). Tissue was gassed continuously with $95 \%$ oxygen $-5 \%$ carbon dioxide during the incubation. The action was stopped with $0.4 \mathrm{~N}$ perchloric acid containing carrier thymidine at $5 \mathrm{mM}$. Samples were removed by being hydrolysed in $0.3 \mathrm{~N} \mathrm{KOH}$ for 90 minutes at $37^{\circ} \mathrm{C}$. DNA was reprecipitated with $10 \%$ perchloric acid. The RNA content of the supernatant was determined using the orcinol reaction. ${ }^{29}$ After standing on ice for 10 minutes, the DNA containing tubes were centrifuged, and the supernatant was discarded. DNA in the residual pellet was solubilised in $10 \%$ perchloric acid, heated to $70^{\circ} \mathrm{C}$ for 20 minutes. The DNA content of the samples was determined by the Burton procedure, ${ }^{30}$ as modified by Giles and Myers. ${ }^{31}$ The incorporation of $\left[{ }^{3} \mathrm{H}\right]$ thymidine into DNA was determined by counting $0.5 \mathrm{ml}$ DNA containing filtrate in a Beckman liquid scintillation system. DNA and RNA content were expressed as micrograms per $100 \mathrm{mg}$ mucosa and DNA synthesis was expressed as disintegrations per minute (dpm) per $\mu \mathrm{g}$ DNA.

\section{STATISTICS}

Results are expressed as mean (SEM). The significance of the difference between means was evaluated using analysis of variance followed by Duncan's test with a confidence value at $\mathrm{p}<0.05$.

\section{Results}

Eight volunteers entered the study and completed the aspirin treatment. The pre-treatment assessment of gastric microbleeding was about $0.38(0 \cdot 14) \mathrm{ml} /$ day (Fig 1). After three days of treatment with aspirin, gastric microbleeding increased significantly $(\mathrm{p}<0.001)$ in all subjects reaching about 7.68 $(0.52) \mathrm{ml} /$ day. After seven days of treatment the microbleeding remained at a value that was not significantly different from that recorded after three days of treatment. Continuation of aspirin treatment for 14 days resulted in a significant attenuation of the rate of gastric microbleeding by about $50 \%$. Two days after aspirin ingestion had stopped gastric microbleeding tended to return towards the pre-treatment value but was still significantly higher than the initial value.

The $\mathrm{pH}$ of gastric content was $5 \cdot 8(0 \cdot 1)$ before the beginning of aspirin treatment, dropped down to $3 \cdot 8(0 \cdot 1)$ at day 3 of aspirin treatment, and did not change significantly from this value during the rest of aspirin treatment.

After three days of treatment with aspirin ( $2 \mathrm{~g}$ per day) plasma salicylate concentration was $10.3(1.3) \mu \mathrm{g} / \mathrm{ml}$ and remained close to this value in all volunteers up to the end of the aspirin ingestion. 


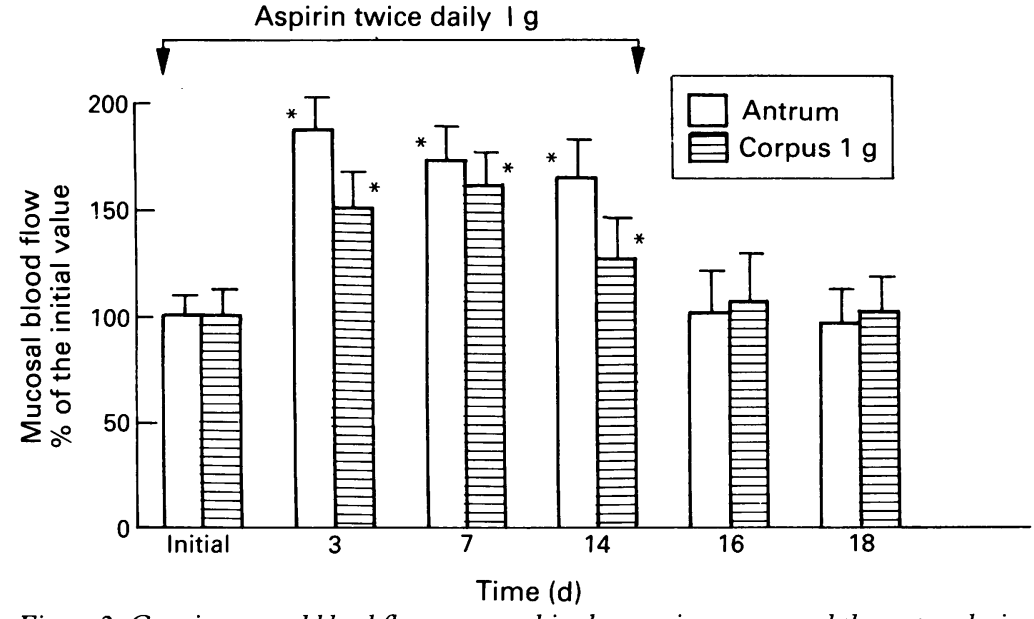

Figure 3: Gastric mucosal blood flow measured in the gastric antrum and the corpus during 14 days of aspirin treatment and four days after aspirin treatment. Mean (SEM) of eight observations in eight subjects. * Shows significant changes $(p<0.05)$ compared with values before aspirin treatment.
Initial gastroscopy did not show any mucosal abnormality in any of subjects tested and the Lanza score was 0 (Fig 2). The gastroscopy performed after three days of aspirin treatment showed numerous and large areas of submucosal haemorrhages located in the fundic mucosa and less in the antral mucosa with the Lanza score reaching an average $3.5(0 \cdot 2)$. In the next examination at day 7 the gastric mucosal damage showed reduction in four subjects and was unchanged in four others with the Lanza score being 3.0 $(0 \cdot 14)$. Continuation of the treatment led to further resolution of the mucosal damage in all subjects examined and only single submucosal haemorrhages were seen at day 14 (Lanza score $1.5(0 \cdot 2))$. This lowered Lanza score was significantly different from that recorded at day 3 and 7 of aspirin treatment. Within four days after aspirin ingestion had finished no evidence of any mucosal damage was obtained in seven subjects but in one case a minor submucosal haemorrhage was seen.

Initial mucosal blood flow in the corpus was higher than in the antrum and averaged 60.6 $(1.9)$ and $50.2(2.4) \mathrm{ml} / \mathrm{min} / 100 \mathrm{~g}$ tissue, respectively (Fig 3 ). Three days treatment with aspirin caused a significant increase in mucosal

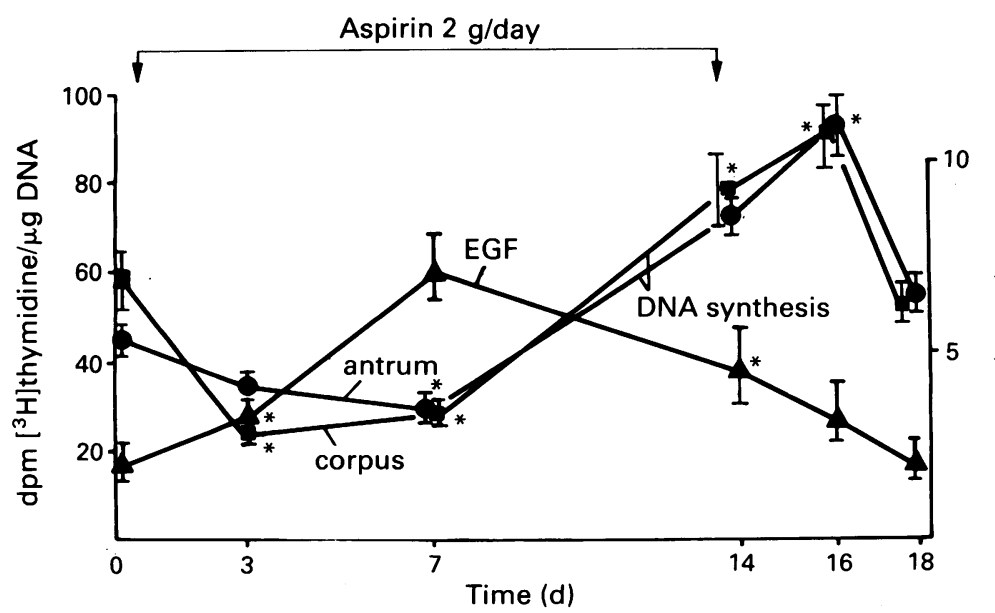

Figure 4: Mucosal DNA synthesis in the corpus and antrum of the stomach during 14 days of continuous aspirin treatment. Mean (SEM) of eight observations in eight subjects.

${ }^{\star}$ Shows significant changes compared with control values. blood flow in both, the gastric corpus by about $51 \%$ and gastric antrum by about $88 \%$. Mucosal blood flow slightly and insignificantly dropped at day 14 (by about $23 \%$ in the corpus and by $24 \%$ in the antrum) but still remained significantly raised compared with the initial values. Blood flow, measured two days after aspirin ingestion was finished, was back to control values.

The concentration of epidermal growth factor in gastric juice measured before the start of aspirin treatment averaged $1 \cdot 8(0 \cdot 2) \mathrm{ng} / \mathrm{ml}$ (Fig 4). After three days of aspirin treatment the concentration of epidermal growth factor was almost doubled $(3.4(0.6) \mathrm{ng} / \mathrm{ml})$ and reached the peak $(7 \cdot 2(1 \cdot 4) \mathrm{ng} / \mathrm{ml})$ after seven days of treatment. After 14 days of treatment, epidermal growth factor concentration was still significantly raised $(4.3(1 \cdot 8) \mathrm{ng} / \mathrm{ml})$, but four days after aspirin administration had finished the concentration of epidermal growth factor in the gastric content was not significantly different from the initial value $(2 \cdot 1$ $(0.4) \mathrm{ng} / \mathrm{ml})$.

Aspirin treatment caused significant changes in the incorporation of ${ }^{3} \mathrm{H}$ thymidine into DNA (Fig 4). After three and seven days of aspirin ingestion DNA synthesis dropped by about $50 \%$ in both the gastric corpus and antral mucosa and was followed by a significant increase at day 14 with the highest value being reached two days after aspirin treatment ended. DNA and RNA concentrations tended to decrease at day 3 of aspirin treatment but this was not statistically significant (Table). At day 7 of aspirin treatment, RNA concentration returned to the pre-treatment value to reach a significant increase in both the gastric corpus and antral mucosa at day 14. The DNA concentrations were not significantly affected throughout the period of aspirin treatment.

In the venous blood drawn before the start of aspirin treatment the coincubation of platelets and PMN without addition of thrombin resulted in the formation of $15(0.6)$ rosettes per vision field showing only a slight association of platelets with leucocytes during the isolation procedure (Fig 5). Addition of thrombin resulted in the increase of the rosette number up to $25 \cdot 0(0 \cdot 7)$. After three days of aspirin treatment there was a significant increase of the rosette number in both unstimulated $(22.0(0.9))$ and thrombin stimulated platelets $(33.0(1 \cdot 5))$. The number of leucocytes with rosettes was increasing during the whole aspirin treatment period and reached the highest value at day $14(26 \cdot 2$ $(1 \cdot 6)$ thrombin unstimulated and $41.3(2 \cdot 2)$ thrombin stimulated platelets). Four days after aspirin treatment the rosette number did not differ from the initial value in both thrombin unstimulated and thrombin stimulated platelets.

\section{Discussion}

This study confirms earlier results that aspirin is harmful to the gastric mucosa ${ }^{2} 8-103233$ but that the gastric mucosa shows a remarkable 
$R N A$ and DNA concentration in the oxyntic and antral mucosa of the stomach during 14 days of aspirin treatment

\begin{tabular}{|c|c|c|c|c|c|c|}
\hline & \multicolumn{6}{|c|}{ Days of aspirin treatment } \\
\hline & 0 & 3 & 7 & 14 & 16 & 18 \\
\hline \multicolumn{7}{|l|}{ Oxyntic gland mucosa } \\
\hline RNA $\mu \mathrm{g} 100 \mathrm{~g}$ tissue & $950(41)$ & $740(19)$ & $970(38)$ & $1140(72)$ & $1290(86)^{\star}$ & $1180(79)^{\star}$ \\
\hline DNA $\mu \mathrm{g} 100 \mathrm{~g}$ tissue & $380(23)$ & $370(52)$ & $400(40)$ & $410(26)$ & $411(29)$ & $430(26)$ \\
\hline \multicolumn{7}{|l|}{ Antral mucosa } \\
\hline RNA $\mu \mathrm{g} 100 \mathrm{~g}$ tissue & $1000(36)$ & $850(46)$ & $980(49)$ & $1230(56)^{\star}$ & $1270(79)^{\star}$ & $1230(87)^{\star}$ \\
\hline DNA $\mu \mathrm{g} 100 \mathrm{~g}$ tissue & $380(38)$ & $360(21)$ & $400(31)$ & $390(20)$ & $420(19)$ & $420(23)$ \\
\hline
\end{tabular}

Values are mean (SEM) of eight observations in eight subjects.

$\star$ =Significant changes compared with control before aspirin treatment.

ability to adapt to repeated exposures to the injurious action of this drug so that macroscopic damage inflicted on the first contact is minimised on repeated challenge. ${ }^{8-10}$

In our study continuous administration of aspirin for 14 days in healthy volunteers resulted in a statistically significant reduction in the extent of gastric damage as determined by endoscopic score and microbleeding from the stomach. Graham et $a l^{8}$ showed that aspirin in humans induced maximal gastric injury within three days of treatment but then the lesions tended to resolve despite continued administration of the drug. We also saw the most pronounced endoscopic damage at the third day of aspirin treatment and this was well correlated with a considerably increased rate of gastric microbleeding. The increase in microbleeding seen by us was greater than that reported previously 3435 but this could be explained simply by the higher dose of aspirin used in our study. This is in keeping with the finding of Pierson et al ${ }^{36}$ who found direct correlation between the dose of aspirin and the rate of gastric microbleeding.

The effect of aspirin on the mucosal blood flow, an important component of the mucosal defence system, remains controversial. Main and Whittle ${ }^{37}$ saw a reduction in mucosal blood flow in rats treated with indomethacin at the dose that inhibited prostaglandin formation. This could be consistent with a prostaglandin mediated mechanism, as prostaglandins are known to enhance mucosal blood flow. ${ }^{38}$ Kauffman ${ }^{39}$ found a decrease in basal gastric mucosal blood flow in conscious

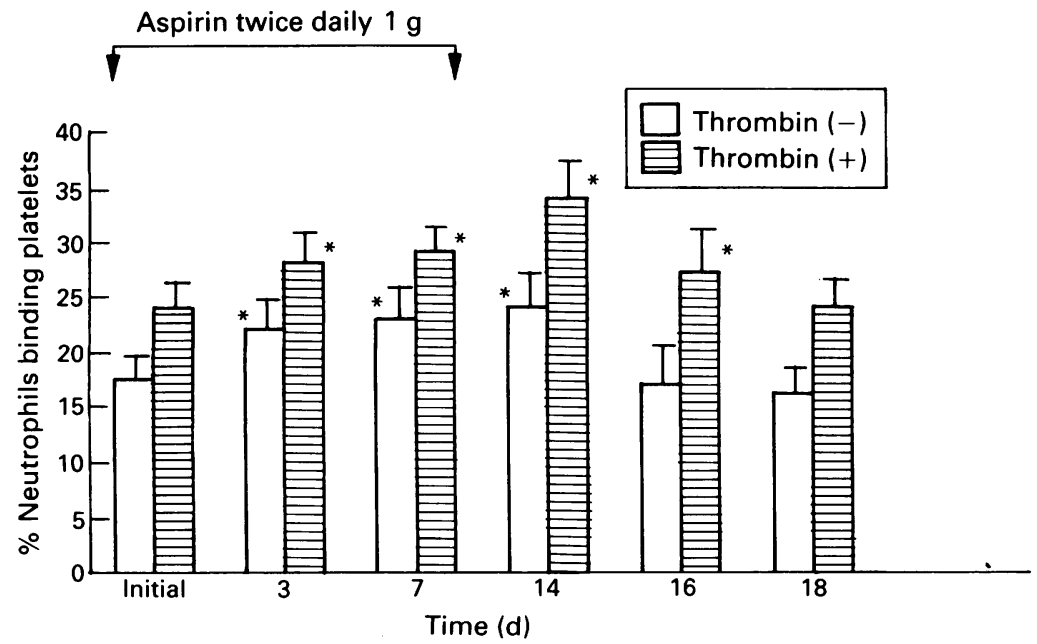

Figure 5: The platelet/neutrophil adherence in eight subjects treated with aspirin for 14 days. Data expressed as mean $(S E M)$. ${ }^{\star}$ Shows significant $(p<0.05)$ change compared with control values. dogs given indomethacin. Both indomethacin and aspirin were also shown to induce rapid microvascular damage and subsequently to reduce mucosal blood flow so the fall in the gastric circulation could result from the widespread haemorrhagic necrosis. ${ }^{7}$ On the other hand, Ashley et al ${ }^{6}$ have shown that aspirin caused the reduction in gastric mucosal blood flow only at the site of damage, with enhancement of blood flow elsewhere with an overall increase in gastric blood flow. This is consistent with our study in which the flow measured in the macroscopically unchanged mucosa was significantly increased during the whole aspirin treatment period. On the other hand Shorrock and Rees ${ }^{40}$ using a similar technique of blood flow measurement to ours but giving indomethacin to healthy volunteers saw a significant reduction in gastric mucosal blood flow after 24 hours administration of this agent and this decrease was closely correlated with maximal mucosal damage. Indomethacin, however, differs from aspirin and exerts a stronger influence on the gastric blood flow than aspirin both in animals and in humans. ${ }^{41}$

In this study, aspirin was used at a dose usually used in arthritic patients. Using this dose, the most profound injury was seen after three days, and in contrast with the study with indomethacin ${ }^{40}$ there was a significant increase in mucosal blood flow. The mechanism of this rather unusual finding of increased blood flow combined with visible mucosal lesions after aspirin in humans is unknown and suggests a difference between indomethacin and aspirin in the action on gastric circulation that is not dependent upon the inhibition of prostaglandin biosynthesis. Studies in rats $^{42}$ showed that aspirin can damage both superficial and deep mucosal microvessels with a widespread destruction of endothelial cells within 15 minutes of injury. In humans, a single dose of aspirin caused evident gastric haemorrhages within one hour followed by widespread petechial haemorrhage and erosions several hours later. ${ }^{43}$ We measured the gastric blood flow before and then three days after the start of aspirin treatment so we could have missed an early reduction in gastric blood flow, which might have occurred after the first aspirin ingestion. The increase in the gastric blood flow seen after three days of aspirin treatment might be an early sign of gastric adaptation to this drug rather than the effect of mucosal damage.

This study confirmed and extended the finding that the human gastric mucosa adapts to continuous treatment with aspirin. ${ }^{8-10}$ The 
mechanisms of this phenomenon are not fully understood but it has been suggested that an increase in the rate of proliferation in the gastric mucosa associated with the rapid renewal of the damaged epithelium play an important part. ${ }^{2} 1944$ The rise in epithelial cell proliferation measured by ${ }^{3} \mathrm{H}$-thymidine uptake in response to four weeks of treatment with aspirin was previously reported in rat fundic mucosa. ${ }^{12}$ In our study on humans the early damaging effect of aspirin was accompanied by some reduction in DNA synthesis without significant changes in RNA or DNA concentrations but later on, despite the continuation of aspirin challenge, an appreciable increase in DNA synthesis and RNA contents was seen. Thus our study shows that the exposure of healthy human gastric mucosa to aspirin leads to initial widespread mucosal damage accompanied by a decrease in cell proliferation seen during the first days of aspirin treatment but then the mucosal regeneration starts. This process is remarkably impressive after 14 days of repeated treatment with aspirin as evidenced by the in vitro $\left[{ }^{3} \mathrm{H}\right]-$ thymidine incorporation into the DNA of gastric biopsy samples, accompanied by the increase of RNA concentration in both corpus and antral mucosa. The fact that DNA synthesis increases but total DNA content does not suggests that there is no accumulation of cells probably because of simultaneous cell exfoliation. ${ }^{45}$ The increase in RNA content suggests that the cells that are present synthetise more protein and eventually other components, which may play a part in adaptation. Our results are in good agreement with a recent report of Levi et al ${ }^{46}$ who found that NSAIDs given long term stimulate the mitotic activity of mucosal cells in patients with arthritis and misoprostol does not reverse this effect. It was proposed that the increase in mitotic activity in gastric glands seen after two weeks of NSAID treatment could be one of the mechanisms underlying gastric adaptation to NSAIDs but no attempts were made to measure the proliferation before the start and after the treatment with NSAIDs in the same subjects.

The factors participating in the enhanced mucosal proliferation during adaptation to NSAIDs have not been identified but Wright et $\mathrm{al}^{47}$ reported that the damage of the human gastrointestinal tract may induce the development of novel cell lineages (from stem cells) that secrete locally epidermal growth factor and this epidermal growth factor could participate in this proliferation of mucosal cells after damage. Although there are no reports showing mRNA for epidermal growth factor in the normal mucosa, increased epidermal growth factor content in the gastric mucosa has been shown in patients with gastritis ${ }^{48}$ suggesting that epidermal growth factor mRNA is present although in small amounts in the intact mucosa. It is probable that epidermal growth factor may be produced locally in larger amounts after the mucosal damage. Indeed a considerable increase in the luminal content of epidermal growth factor was seen in our subjects treated with aspirin and this could contribute to the stimulation of DNA synthesis and mucosal cell proliferation. Although the salivary origin of this epidermal growth factor was largely excluded by aspiration of gastric luminal content, the possibility exists that the salivary epidermal growth factor entering the stomach was taken up by the mucosa and released into the gastric lumen upon the mucosal damage by aspirin. Although epidermal growth factor receptors are localised predominantly to the basolateral aspect of the cells in the proliferative zone, ${ }^{49} 50$ after mucosal damage induced by aspirin, luminal epidermal growth factor may have access to these receptors to initiate cell proliferation and mucosal regeneration. This is supported in our study by the fact that the increase in epidermal growth factor production came before the rise in DNA synthesis and RNA content in the mucosa exposed to aspirin.

It has been reported recently that adhesion of platelets to neutrophils is selectively mediated by the newly recognised selectin $P$, called PADGEM. ${ }^{23}$ PADGEM has been found in megakariocytes and in the endothelial cells within the Weibel-Palade bodies. Expression of PADGEM on the endothelial cell membrane initiates the adhesion of neutrophils to endothelium and their migration. ${ }^{1415}$ Wallace et $a l^{1415}$ and recently Lee et $a l^{16}$ suggested that neutrophils play a crucial part in experimental damage in rats including the mucosal injury caused by NSAIDs. In our study in humans it was not possible to measure the adherence of leucocytes to the endothelium in the gastric mucosa. Therefore, we studied the activation of leucocytes in peripheral blood by determination of platelet to neutrophil association as suggested by Jungi. ${ }^{22}$ This was thought to be reasonable because the PADGEM mediates the adherence of platelets and endothelium to neutrophils. Recently, Dembinska-Kiec et al ${ }^{51}$ in experiments in vitro found that iloprost inhibits, whereas aspirin stimulates the expression of PADGEM and promotes the adherence of platelets to neutrophils. Our study in vivo confirmed that aspirin treatment resulted in the activation of neutrophils and the increase in platelet to neutrophil adherence both mediated by PADGEM. Similar data were obtained by others ${ }^{5253}$ who also saw leucocyte adherence to vessels wall after aspirin treatment. Miura et $a l^{54}$ recently showed that accumulation of neutrophils in the intestinal mucosal microcirculation occurred within hours of indomethacin administration and this came before the development of intestinal lesions. It is probable that activated (by aspirin) granulocytes emigrate from blood vessels into tissues ${ }^{16}$ and that this contributes to the mucosal damage seen in our endoscopic examination. In our study platelet/neutrophil adherence was significantly enhanced after three days of treatment and was maintained at a higher value during the whole period of aspirin treatment reaching the highest value at day 14 in both thrombin 
unstimulated and thrombin stimulated platelets. As the adhesion of leucocytes to the endothelium is a prerequisite for their migration from the blood into tissues the observed activation of leucocytes could contribute to the early aspirin induced gastritis ${ }^{55}$ but may also play a part in subsequent gastric adaptation to aspirin. Support for this idea is our finding that the peak increase in granulocytes activation occurred when the full adaptation to aspirin (decrease of endoscopic score and microbleeding) was seen. Additionally, the support for the implication of neutrophils in aspirin induced mucosal damage originates from the study of Wallace et $a l,{ }^{15}$ who saw that administration of monoclonal antibodies directed against the leucocyte adhesion glycoprotein largely prevents the epithelial cell and microvascular injury caused by aspirin or indomethacin. Aspirin seems to enhance the adherence of neutrophils to the vascular wall by increasing the release of proinflammatory mediators including leukotriene $\mathrm{B}_{4}$ platelet activating factor, and others. ${ }^{1416}$

1 Levy R, Siegel HI, Glass GBJ. Effects of salicylates on the canine stomach: a morphological and histochemical canine stomach: a morphological and
study. Gastroenterology 1972; 62: 970-80.

2 McCarthy DM. NSAID-induced gastrointestinal damage. A critical review of prophylaxis and therapy. $f$ Clin Gastroenerol 1990; 12 (suppl 2): S13-20

3 Ivey KJ. Mechanisms of NSAID-induced gastric damage actions of therapeutic agents. $A m \mathcal{F}$ Med $1988 ; 84$ (supp 2A): $41-8$.

4 Hudson N, Hawthorne AB, Cole AT, Jones PDE, Hawkey CJ. Mechanisms of gastric and duodenal damage and protection. Hepatogastroenterology 1992; 39 (suppl 1): 31-6.

5 Kitahora T, Guth PH. Effect of aspirin plus hydrochloric acid on the gastric mucosal microcirculation Gastroenterology 1987; 93: 810-7.

6 Ashley SW, Sonnenschein LA, Cheung LY. Focal gastric mucosal blood flow at the site of aspirin-induced ulceration. Am F Surg 1985; 149: 53-9.

7 Sandor Z, Szabo S. Pharmacologic approaches and pathogenic basis for NSAID gastropathy, prevention and treatment. Proc Gastroenterol 1991; 15: 30-43.

8 Graham DY, Smith JL, Dobbs SM. Gastric adaptation occurs with aspirin administration in man. Dig Dis Sci 1983; 28: 1-6.

9 Olivero JI, Graham DY. Gastric adaptation to nonsteroidal anti-inflammatory drugs in man. Scand $\mathcal{f}$ Gastroenterol 1992; 27: 193, 53-8.

10 Graham DY, Smith JL, Spjut HJ, Torres E. Gastric adaptation. Studies in humans during continuous aspirin administration. Gastroenterology 1988; 85: 327-33.

11 St John DBJ, Xeomans ND, McDermott MB, de Boer WGRM. Adaptation of the gastric mucosa to repeated administration of aspirin in rat. Am $\mathcal{f}$ Dig Dis 1973; 18: administra $881-6$.

12 Eastwood GL, Quimby GF. Effect of chronic aspirin ingestion on epithelial cell proliferation in rat fundus, antrum, and duodenum. Gastroenterology 1982; 82 852-6.

13 Hiroshi Asako, Kubes P, Wallace IL, Wolf RE, Granger DN. Modulation of leukocyte adhesion in rat mesenteric venules by aspirin and salicylate. Gastroenterology 1992 103: $146-52$.

14 Wallace JL. Non-steroidal anti-inflammatory drug gastropathy and cytoprotection. Pathogenesis and mechanisms re-examined. Scand f Gastroenterol 1992; 27 (suppl 192): re-exam

15 Wallace IL, Keenan CM, Granger DN. Gastric ulceration induced by nonsteroidal anti-inflammatory drugs is neutrophil dependent mechanism. Am F Physiol 1990; 259: G462-7.

16 Lee M, Keith A, Lee E, Feldman M. Aspirin-induced acute gastric mucosal injury is a neutrophil-dependent proces in rats. Am $\mathcal{F}$ Physiol 1992; 263: G920-6.

17 Vaananen P, Meedings JB, Wallace JL. Role of reactive oxygen metabolites in experimental NSAID gastropathy [Abstract]. Gastroenterology 1991; 100: 1846.

18 Hattori R, Hamilton KK, Fugare RD, McEvert RP, Sims PJ. Stimulated secretion of endothelial von Willebran factor is accompanied by rapid redistribution to the cell surface of the intracellular granule membrane protein GMP-1 40. F Biol Chem 1989; 264: 7768-71.

19 Levi S, Goodland RA, Lee CY, Walport MJ, Wright NA, Hodgson HJE. Effect of nonsteroidal anti-inflammatory drugs and misoprostol on gastrointestinal epithelial proliferation in arthritis. Gastroenterology 1992; 102. proliferation 11 .
20 McCarthy DM. Pathogenic mechanism of gastroduodenal injury: nonsteroidal anti-inflammatory drugs. Gastroenterology 1991; 7: 876-80.

21 Saltzman A. Fluorometric method for the estimation of salicylate in blood. $f$ Biol Chem 1948; 174: 399-404.

22 Jungi TW, Spycher MO, Nydegger UE, Barandum S. Platelet-leukocyte interaction: selective binding of thrombin stimulated platelets of human monocytes, polymorphonuclear leukocytes and related cell lines. Blood 1986; 77: 629-35.

23 Boyum A. Isolation of mononuclear cells and granulocytes from human blood. Isolation of mononuclear cells by one centrifugation and sedimentation at $1 \mathrm{~g}$. $\mathrm{f}$ Clin Lab Invest 1968; 21 (suppl 97): 77-82.

24 Hsu-Lin SC, Berman CL, Furie BC, August D, Furie B. A platelet membrane protein expressed during platelet activation. F Biol Chem 1984; 259: 9121-6.

25 Konturek SJ, Kwiecien N, Obtulowicz W, Polanski $M$ Kopp B, Oleksy J. Comparison of prostaglandin $\mathrm{E}_{2}$ and ranitidine in prevention of gastric bleeding by aspirin in man. Gut 1981; 24: 89-93.

26 Lanza FL. A review of mucosal protection by synthetic prostaglandin $\mathrm{E}$ analogues against injury by nonsteroidal anti-inflammatory drugs. Scand $\mathcal{f}$ Gastroenterol 1989; 24 (suppl 163): 36-43.

27 Konturek JW, Bielański W, Konturek SJ, Bodał J, Olesky J. Distribution and release of epidermal growth factor in Distribution and release of ep
man. Gut 1989; 30: 1194-200.

28 Chung R, Bruch D, Dearlove J. Endoscopic measurement of gastric blood flow by laser Doppler velocimetry: effect of chronic esophageal variceal sclerosis. Am Surg 1988 54: $116-20$.

29 Ceriotti G. Determination of nucleic acids in animal tissues f Biol Chem 1955; 214: 59-63.

30 Burton K. A study of the conditions and mechanisms of the diphenylamine reaction for the colorimetric estimation of deoxyribonucleic acid. Biochem f 1956; 62: 315-7.

31 Giles KW, Myers A. An improved diphenylamine method for the estimation of deoxyribonucleic acid. Nature 1965; 206: $93-7$.

32 Lanza FL. Endoscopic studies of gastric and duodenal injury after the use of ibuprophen, aspirin and other nonsteroidal anti-inflammatory agents. $A m \mathcal{F}$ Med 1984; 77 19-24.

33 Fries JF, Miller SR, Spitz PW, Williams CA, Hubert HB, Bloch DA. Identification of patients at high risk for gastropathy associated with NSAID use. $\mathcal{F}$ Rheumatol 1990 17 (suppl 20): 12-9.

34 Hagel HJ, Wild H, Ruppin H, Kachel G, Domschke W Gastrale Cytoprotection durch Antazida und Schleimhautadaptation an Acetylsalicylsäure. GastroEntero-Hepatologie 1984; 4: 2-8.

35 Kitchingman G, Prichard PJ, Daneshmend TK, Walt RP, Hawkey CJ. Enhanced gastric mucosal bleeding with low dose aspirin and its reduction by ranitidine. $\mathrm{Br} f \mathrm{Clin}$ Pharmacol 1989; 28: 581-5.

36 Pierson RN, Holt PR, Watson RM, Keatling RR. Aspirin and gastrointestinal bleeding; chromate 51 blood loss studies. Am ₹ Med 1961; 31: 259-65.

37 Main IHM, Whittle BJR. Investigation of the vasodilatator and antisecretory role of prostaglandins in the rat gastric mucosa by use of nonsteroidal anti-inflammatory drugs. Br f Pharmacol 1975; 53: 217-24

38 Chenung LY. Topical effect of 16.16-dimethyl prostaglandin $\mathrm{E}_{2}$ on gastric mucosal blood flow in dogs. Am 7 Physiol 1980; 238: G514-9.

39 Kauffman GL Jr, Aures D, Grossman MI. Indomethacin decreases basal gastric blood flow. Gastroenterology 1979; 76: $1165-73$.

40 Shorrock CJ, Rees WDW Mucosal adaptation to indomethacin induced gastric damage in man - studies on morphology, blood flow, and prostaglandin metabolism Gut 1992; 33: 164-9.

41 Konturek SJ, Kwiecien N, Obtulowicz W. Effect of carprofen and indomethacin on gastric function, mucosal integrity and generation of prostaglandin in man Hepatogastroenterology 1982; 29: 267-73.

42 Tarnawski A, Stachura J, Gergely H, Hollander D. Gastric mucosal epithelium; a major target for aspirin-induced injury and arachidonic acid protection, and ultrastructural analysis in the rat. Eur $\mathcal{F}$ Clin Invest 1990; 20: 432-40.

43 O'Laughlin JC, Hoftrezer JW, Ivey KJ. Effect of aspirin on the human stomach in normals: endoscopic comparison of damage produced one hour, 24 hours, and 2 weeks after administration. Scand 7 Gastroenterol 1981; 67: after adm.

44 Baumgartner A, Kölz HR, Halter F. Indomethacin and turnover of gastric mucosal cell in the rat. $A m \mathcal{F}$ Physio 1986; 250: G830-5.

45 Ruppin H, Person B, Robert A, Domschke W. Gastric cytoprotection in man by prostaglandin $\mathrm{E}_{2}$. Scand $\mathcal{f}$ Gastroenterol 1981; 16: 647-52.

46 Levi S, Goodland RA, Lee CY, Stomp G, Walport MJ, Wright NA, et al. Inhibitory effect of non-steroidal anti-inflammatory drugs on mucosal cell proliferation associated with gastric ulcer healing. Lancet 1990; 336: 840-3.

47 Wright NA, Pke C, Elia G. Induction of novel epidermal growth factor secreting cell lineage by mucosal ulceration in human gastrointestinal stem cells. Nature 1990; 343: $82-5$.

48 Jankowski J, Al-Rawi HJ, Johnston DA, Hopwood D, Filipe MI, Coghill G, et al. Growth regulatory peptides in gastric mucosa. Clin Sci 1992; 82: 581-7. 
49 Zimmerman RP, Gates TS, Boehner CG, Mantyn PW. Epidermal growth factor receptors in the canine antrum. Peptides 1989; 9: 1411-4.

50 Sottili M, Sternini C, Brechta NC, Lezoche E, Walsh JH Transforming growth factor alfa receptor binding sites in the canine gastrointestinal tract. Gastroenterology 1992; 103: 1427-36.

51 Dembińska-Kieć A, Imuda H, Gryglewski R. The effect of exogenous and endogenous nitric oxide and prostanoids on the adherence of platelets to neutrophils. Int $\mathcal{F}$ Tissue React 1993; 15: 56-64.

52 Asako H, Kubes P, Wallace J, Gaginella T, Wolf RE,
Granger DN. Indomethacin-induced leukocyte adhesion in mesenteric venules; role of lipooxygenase product. Gastroenterology 1992; 103: 146-52.

53 Kitahora T, Guth PH. Effect of aspirin plus hydrochloric acid on the gastric mucosal microcirculation. Gastroenterology 1987; 93: 810-7.

54 Miura S, Suemotsu M, Tanaka S. Microcirculatory disturbance in indomethacin-induced intestinal ulcer. $A m$ Physiol 1991; 261: G213-9.

55 Rot A. Endothelial cell binding of NAP-1/IL-8: role of neutrophil emigration. Immunol Today 1992; 13: 291-6. 